RECENT ADVANCES

\title{
The intensive care of infants with hypoplastic left heart syndrome
}

\author{
U Theilen, L Shekerdemian
}

Arch Dis Child Fetal Neonatal Ed 2005;90:F97-F102. doi: 10.1136/adc.2004.051276

Until a little over two decades ago, hypoplastic left heart syndrome was considered an inoperable and fatal condition, with most deaths occurring in early infancy, and almost all of those affected dying before their first birthday. However, the advent of surgical palliation and advances in peri-operative care, have offered hope to these patients and their families.

See end of article for authors' affiliations

......................

Correspondence to: Dr L Shekerdemian, Intensive Care Unit, Royal Children's Hospital, Flemington Road, Parkville, Victoria 3052, Australia; lara.shekerdemian@ rch.org.au

Accepted 7 June 2004
$\mathrm{H}$ ypoplastic left heart syndrome (HLHS) is a continuum which can affect all left sided cardiac structures, from the mitral valve to the aortic arch. Since Norwood's first description of surgical palliation in 1981, ${ }^{1}$ HLHS has been managed either by staged palliation in the majority of cases, or, in a minority, by primary discuss the early medical and surgical management of the neonate with HLHS, focusing on the evolution of new surgical strategies, and on the changing emphasis of peri-operative circulatory management on the intensive care unit.

\section{INTENSIVE CARE OF THE INFANT WITH HLHS}

The primary goal of peri-operative care of the neonate undergoing stage 1 palliation (Norwood operation or its modifications) is to optimise systemic oxygen delivery and organ perfusion. This must be addressed as early as possible, and in most cases the critical period begins before transfer to a cardiac centre. ${ }^{2}$

\section{PREOPERATIVE STABILISATION \\ The arterial duct}

In the preoperative period, systemic perfusion is critically dependent on a patent arterial duct, a non-restrictive inter-atrial communication, and good right ventricular function. The arterial duct is the main source of systemic blood flow, and provides retrograde filling to the aortic arch, diminutive ascending aorta, and coronary arteries. Babies with HLHS require prostaglandin E to maintain ductal patency. This should be commenced in the delivery room if the diagnosis has been made prenatally, or otherwise as soon as the diagnosis is suspected. ${ }^{2}$ Early intervention with prostaglandin maximises systemic perfusion, and optimises the condition of the infant before surgery.

\section{The inter-atrial communication}

In contrast to the majority of HLHS patients, in whom low systemic perfusion is in the context of cardiac transplantation. In this article we will excessive pulmonary blood flow, an important subgroup may have inadequate inter-atrial mixing due to a restrictive atrial septal defect (ASD). This results in global hypoperfusion, with profound hypoxaemia and acidosis, severe pulmonary venous hypertension, and overwhelming pulmonary venous congestion on chest $x$ ray. These infants are generally unresponsive to measures aimed at improving pulmonary flow such as aggressive mechanical ventilation with high inspired oxygen fractions or nitric oxide, and if left untreated they rapidly develop progressive pulmonary venous hypertension. This is associated with increased mortality in infants with HLHS. ${ }^{3}$

A restrictive ASD requires urgent intervention. If this has been diagnosed antenatally, delivery should be planned in a centre able to urgently institute cardiopulmonary bypass. Decompression can be achieved by open surgical septectomy, or by the transcatheter route. In a recent series of 355 neonates with HLHS, 21 required interventional cardiac catheterisation for creation or enlargement of restrictive or absent ASD. ${ }^{5}$ A number of transcatheter techniques have been used. The Rashkind balloon atrial septostomy (often unsuccessful) and blade septectomy (carrying a high risk of tamponade) have been more recently superseded by techniques using transatrial needle puncture followed either by serial balloon dilatation (septoplasty) or stent implantation (see fig 1 ).

Following relief of inter-atrial restriction, a few days should be allowed before stage 1 palliation. This allows for resolution of organ damage secondary to severe hypoxia, and for improvement in lung function. ${ }^{5}$

\section{Respiratory management}

All neonates with HLHS should have continuous monitoring of their oxygen saturation. In the preoperative setting, the systemic, pulmonary, and coronary circulations run in parallel, and are all supplied by the right ventricle. ${ }^{6}$ The balance between pulmonary flow (Qp) and systemic flow (Qs) is critically important: an excess of one will by definition compromise the other. The balance between pulmonary and systemic flow depends on the relative resistances in the two circulations. Deliberate or inadvertent manipulation of the pulmonary resistance (primarily with changes in respiratory management), or of the systemic resistance (using pharmacotherapy), will result

Abbreviations: ASD, atrial septal defect; ECLS, extracorporeal life support; HLHS, hypoplastic left heart syndrome; PVR, pulmonary vascular resistance 


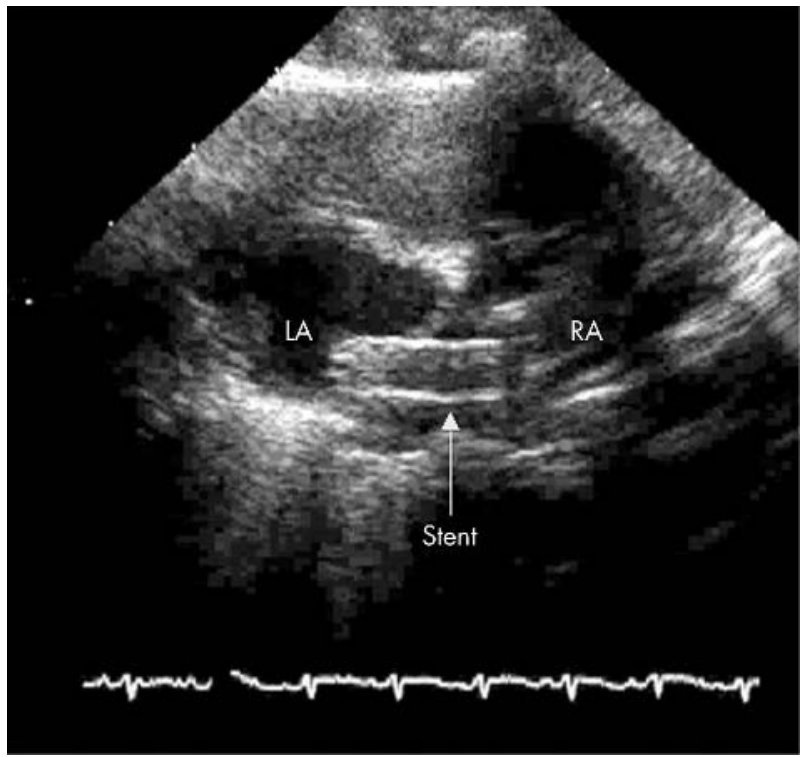

Figure 1 Transthoracic echocardiogram of infant with HLHS, showing a stent across the inter-atrial septum, allowing free mixing of blood between the left atrium (LA) and right atrium (RA).

in changes in this balance in favour of one or other circuit. The most common early sign of pulmonary overcirculation is an increase in arterial oxygen saturation, and seemingly minor increases in saturation can result in significant increases of pulmonary flow. ${ }^{7}$ If left untreated, the later, more sinister manifestations of systemic hypoperfusion may result; these are metabolic acidosis, diastolic hypotension, coronary ischaemia, and myocardial and end-organ dysfunction. The sequelae of this-mesenteric ischaemia leading to severe necrotising enterocolitis, ${ }^{8}$ and hypoxic-ischaemic or haemorrhagic cerebral damage-can ultimately preclude surgical intervention.

Initial respiratory care of the neonate with known or suspected HLHS should be targeted at avoiding pulmonary overcirculation. This pre-emptive approach is by far preferable to treatment of unwanted sequelae. Pulmonary blood flow in the neonate is exquisitely sensitive to alveolar oxygen, carbon dioxide, and $\mathrm{pH}$. Immediate management should therefore include the routine avoidance of factors which increase pulmonary flow (such as excessive oxygen administration or respiratory alkalosis), or with early intervention using strategies which modestly increase pulmonary vascular resistance (PVR), and the careful introduction of systemic vasodilators. The basic goals of respiratory management of infants with HLHS are described in box 1. Mechanical ventilation is not mandatory in stable infants; indeed, in a series of 171 babies with HLHS, $30 \%$ did not require preoperative ventilatory support. ${ }^{9}$ However, careful monitoring is essential.

A number of ventilatory manipulations aimed at increasing PVR have been described for infants with pulmonary overcirculation, at risk of systemic hypoperfusion. Hypoxic gas $\left(14-20 \% \quad \mathrm{FiO}_{2}\right)$ can be delivered by adding nitrogen to ventilator or ambient gases. ${ }^{10}$ Arterial $\mathrm{pCO}_{2}$ can be deliberately increased by hypoventilation or delivery of additional carbon dioxide (2-5\%). ${ }^{11}{ }^{12}$ Deliberate hypoventilation carries the risk of progressive atelectasis and is probably the least favourable method. Data comparing hypoxic and hypercarbic gas mixtures are limited. In an animal model, the ratio of pulmonary-to-systemic blood flow (Qp:Qs) responded similarly to both manoeuvres. ${ }^{13}$ In the only published clinical comparison of hypoxia (17\%) and hypercarbia $\left(\mathrm{FiCO}_{2} 2.7 \%\right)$,
Box 1: Guide to immediate respiratory management of infants prior to surgery for HLHS

\section{Indications for intubation}

- Apnoeas or severe respiratory distress

- Significant metabolic acidosis*

- Significant pulmonary overcirculation*

- Severe myocardial dysfunctiont

*Markers of systemic hypoperfusion with a high risk of endorgan dysfunction; persistent tachypnoea

†Perinatal asphyxia and metabolic acidosis in the "collapsed" neonate; coronary hypoperfusion in the infant with excessive pulmonary flow

$$
\begin{aligned}
& \text { Ventilation } ¥ \text { and target blood gases } \\
& \text { - } \mathrm{PaCO}_{2} 35-45 \mathrm{~mm} \mathrm{Hg} \\
& \text { - } \mathrm{pH} 7.35-7.40 \\
& \text { - } \mathrm{PaO}_{2} 30-45 \mathrm{~mm} \mathrm{Hg} \\
& \text { - } \mathrm{SaO}_{2} 70-85 \%
\end{aligned}
$$

\pm Ventilate initially using $\mathrm{FiO}_{2} 0.21$, PEEP $4-5 \mathrm{~cm} \mathrm{H}_{2} \mathrm{O}$ Haemoglobin should be maintained at 140-160 g/l

10 anaesthetised infants with unoperated HLHS were evaluated in a prospective, randomised, crossover trial. ${ }^{14}$ Both manoeuvres similarly decreased Qp:Qs and arterial oxygen saturations. Hypercarbia, but not hypoxia, increased systolic and diastolic blood pressure, and also increased the mixed venous and cerebral oxygen saturations, suggesting improved systemic oxygen delivery.

\section{Pharmacotherapy}

Intravenous vasodilators are frequently used to optimise systemic blood flow, and two main classes of agent are used in the preoperative setting. Sodium nitroprusside is a vasodilator with a rapid onset of action, and has the potential advantages of a relatively titratable dose dependent effect, and a short half life. ${ }^{15}$ Phenoxybenzamine, an $\alpha$-adrenergic receptor blocker, was shown to reduce Qp:Qs in a prospective study of 15 patients with HLHS. ${ }^{16}$ Higher superior vena cava saturation and a narrower arteriovenous oxygen difference were noted, indicating improved systemic oxygen delivery with phenoxybenzamine. In another study, the use of perioperative phenoxybenzamine was associated with increased survival. ${ }^{17}$ Systemic vasodilators should be used carefully in order to avoid excessive hypotension, which can to an extent be avoided if the intravascular volume status is adequate. However, systemic blood pressure is a poor marker of systemic blood flow. A lower mean arterial pressure in the infant who is systemically vasodilated is preferable to hypertension with systemic vasoconstriction.

Inotropes are not specifically indicated in the preoperative setting, but may be beneficial in some individuals. Infants with severe metabolic acidosis at presentation, and those with coronary ischaemia secondary to hypoperfusion are at particular risk of right ventricular dysfunction. In this situation, a low dose infusion of an inotrope such as dobutamine $(5-10 \mu \mathrm{g} / \mathrm{kg} / \mathrm{min})$ may improve ventricular function.

\section{Prenatal diagnosis}

Prenatal diagnosis has allowed for more careful planning of delivery and immediate postnatal care of infants with HLHS. Although the reported impact of prenatal diagnosis on overall 
survival is variable, infants diagnosed prenatally are certainly less likely to experience the sequelae of pulmonary overcirculation or acidosis. Prenatal diagnosis is associated with improved neurological outcome ${ }^{18}$ and with a lower incidence of preoperative acidosis and ventricular dysfunction, and the need for less inotropic support. ${ }^{19}$ For the minority with a restrictive ASD, prenatal diagnosis allows for immediate postnatal intervention. These data undoubtedly reinforce the importance of early pre-emptive intensive care of neonates with HLHS.

\section{SURGERY FOR HLHS}

Staged surgical palliation begins with the Norwood operation, ${ }^{1}$ or one of its modifications, typically performed during the first week of life. The aim of stage 1 palliation is to enlarge the aorta and to establish its continuity with the right ventricle; to provide free mixing of the pulmonary and systemic venous blood through an atrial septectomy; and to provide the lungs with flow through a systemic-to-pulmonary artery modified Blalock-Taussig (BT) shunt, or latterly via a conduit between the right ventricle and pulmonary arteries.

\section{Right ventricle to pulmonary artery conduit: a recent modification of stage 1 palliation (fig 2)}

Survival of infants born with HLHS has steadily improved since the first description of staged palliation by Norwood and colleagues. Historically, the use of an RV-PA conduit as the source of pulmonary flow had been abandoned in the early 1980s, due to high mortality. However, in retrospect this outcome was probably related to the generous diameter of the conduits ( $8 \mathrm{~mm}$ or more), resulting in massive pulmonary flow and systemic hypoperfusion, rather than the concept itself.

Recently, this approach has been revived, using smaller (4-6 mm) and therefore more limiting conduits, with encouraging results. ${ }^{20} 21$ The so-called "Sano" modification has become increasingly popular in major institutions around the world. Though still early in its evolution, the overwhelming impression from major centres is that the early postoperative course of infants with a conduit is smoother than for those with a BT shunt. ${ }^{132223}$ A prospective randomised comparison of the two surgical techniques may never be feasible, but a number of retrospective cohort

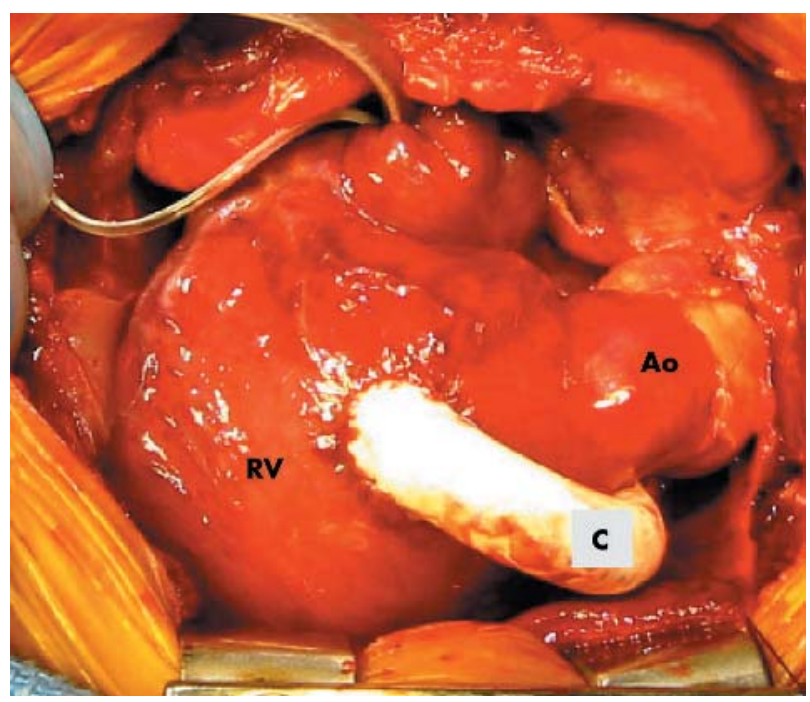

Figure 2 Intra-operative photograph after modified stage 1 palliation, showing the neo-aorta (Ao) and a conduit (C) between the right ventricle (RV) and pulmonary artery (not seen). comparisons have now been published. While recognising their limitations in design and size, and relatively short follow up period, results have been remarkably uniform, and encouragingly in favour of the use of a conduit rather than a shunt.

Systemic perfusion and diastolic blood pressure are generally better maintained after the conduit procedure, and active manipulation of pulmonary blood flow (beyond standard measures) is rarely necessary. ${ }^{21}$ An important advantage of the conduit over the shunt is the maintenance of diastolic coronary perfusion, avoiding the "run-off" which can potentiate myocardial ischaemia in the latter group. This is supported by a number of observational studies which have reported a higher diastolic pressure in patients with a conduit; ${ }^{21}{ }^{23-25}$ and echocardiographic data showing that infants with conduit palliation have no diastolic flow reversal in the aortic arch, in contrast to those with a BT shunt. We have recently shown that these encouraging early signs may be translated into improved right ventricular performance in the convalescent phase. ${ }^{26}$

Clearly, as with any new technique where long term results are not yet available, one must be cautious in overinterpreting the current data. Indeed, there are theoretical concerns regarding the long term implications of a right ventriculotomy in the conduit modification. However, right ventricular failure or arrhythmias have failed to materialise so far. Furthermore, our tissue Doppler data, ${ }^{26}$ catheterisation data of others, ${ }^{25}$ and increased survival to stage 2 palliation ${ }^{23}$ would all suggest improved, rather than diminished right ventricular function in patients with a conduit.

\section{POSTOPERATIVE INTENSIVE CARE AFTER STAGE 1 PALLIATION}

Stage 1 palliation, whether with a classical Norwood operation or with the conduit modification, is a complex procedure, which imposes profound physiological changes on a precarious substrate. Some infants have been in a suboptimal condition preoperatively, and all are subjected to a long period of cardiopulmonary bypass and aortic crossclamp, with deep hypothermia and, in the majority of patients, a period of circulatory arrest. The early postoperative period therefore imposes on these infants the major, immediate demands of adapting to a new circulation, while recovering from a long open heart procedure.

Again, the key to the intensive care of infants after stage 1 palliation is to optimise systemic oxygen delivery, and to act early on any disturbances of this. This is achieved with the combination of careful monitoring, avoidance of factors which lead to excessive pulmonary flow, maintenance of haemoglobin level, optimisation of ventricular performance, and systemic afterload reduction. Historically, early postoperative care of the Norwood patient focused on ventilatory manipulation of PVR to limit pulmonary blood flow. This often subjected the infants to a degree of acidosis which we now recognise as being undesirable. Over recent years, smaller and more limiting BT shunts, the advent of the conduit, and the more routine and liberal use of systemic vasodilators, have somewhat obviated the need for such aggressive control of PVR while appropriately optimising systemic perfusion.

\section{Haemoglobin}

The important contribution of haemoglobin to systemic oxygen delivery should not be underestimated. In the hypoplast, where systemic saturation is kept relatively low, haemoglobin should be maintained around 140-160 g/l to maximise tissue oxygenation. 


\section{Monitoring of mixed venous oxygen saturation}

The adequacy of systemic oxygen delivery, which is so critical, and so variable, is paradoxically difficult to assess. An increasing or persistent metabolic acidosis, or an increased serum lactate, may simply confirm that perfusion is under threat or already compromised. Furthermore, these parameters are not continuously monitored, and therefore give only periodic information. Mixed venous oxygen saturation provides a useful, continuous surrogate measure of the efficiency of systemic oxygen delivery in the functionally univentricular circulation, ${ }^{27}$ and can be used to guide therapy with systemic vasodilators. ${ }^{16}{ }^{17}$

In the infant after stage 1 palliation, mixed venous saturation can be continuously monitored using a cooximeter placed directly into the SVC at the time of surgery. ${ }^{28}$ Although the absolute numbers obtained by this method are not always accurate, the trend in data generated by a well positioned co-oximeter can be useful, with subtle changes often preceding changes in other haemodynamic parameters. A falling saturation would suggest increased tissue oxygen extraction, towards the anaerobic threshold, ${ }^{29}$ and most importantly should stimulate us to search for a cause. ${ }^{17}$

\section{Ventricular performance}

Systemic oxygen delivery after stage 1 palliation can be compromised by two components of right ventricular performance: impaired contractility, and tricuspid regurgitation. Impaired systolic function is an inevitable consequence of bypass related myocardial injury, and can be exacerbated by coronary ischaemia. Ventricular contractility and competence of the tricuspid valve should be assessed using echocardiography. Right ventricular performance can then be optimised with inotropic therapy and appropriate afterload reduction using vasodilators, while avoiding factors which may result in excessive pulmonary blood flow and reduced coronary perfusion.

\section{Pharmacotherapy}

Most patients after stage 1 palliation require inotropes to maintain cardiac contractility. Dobutamine and dopamine are both appropriate for this role, though the additional vasodilatation afforded by dobutamine would make this the drug of choice in some centres. Phosphodiesterase-3 inhibitors such as milrinone are "inodilators", which improve systemic oxygen delivery by producing a combination of inotropic and vasodilatory effects. Milrinone has recently been shown to prevent the development of a low cardiac output state in selected children after cardiac surgery, ${ }^{30}$ and is being increasingly used in infants early after stage 1 palliation. The use of pure systemic vasodilators in addition to inotropes, in the palliated circulation has a number of desirable effects. Peripheral vasodilatation results in afterload reduction, and improved cardiac output and systemic perfusion, and reduces tricuspid regurgitation. Many centres now routinely use phenoxybenzamine intra-operatively and postoperatively after stage 1 palliation, and there is some evidence to suggest that this, in combination with other advancements in peri-operative management, results in improved systemic oxygen delivery, and improves outcome. ${ }^{16} 172831$ Interestingly, higher levels of arterial oxygen are much better tolerated, and may even improve systemic oxygen delivery in the presence of aggressive afterload reduction. ${ }^{32} 33$ In our institution, intravenous dilators are commenced in the operating room or early after surgery in the majority of patients; and once enteral feeds have been established, an oral vasodilator such as captopril is introduced.

\section{Ventilation}

All infants require mechanical ventilation postoperatively, and initial target blood gases are in general similar to those preoperatively-with a normal $\mathrm{pH}$ and $\mathrm{CO}_{2}$, and an arterial $\mathrm{PO}_{2}$ of less than $40 \mathrm{~mm} \mathrm{Hg}$. The pulmonary vasculature after surgery is often labile, and factors which may give rise to unwanted increases in pulmonary blood flow, such as hyperventilation, should be routinely avoided. If however, despite all of the above measures, there is persisting oversaturation with evidence of inadequate systemic oxygen delivery, then the addition of nitrogen to give hypoxic inspiratory gas mixtures can be considered. There is little, if any evidence to show that this manoeuvre has any more than a cosmetic effect-in other words, hypoxic gas effectively reduces the arterial oxygenation, without any convincing effect on systemic oxygen delivery.

\section{Extracorporeal life support}

Extracorporeal life support (ECLS) has been used to support many children with refractory cardiopulmonary dysfunction after surgery for congenital heart disease, with a hospital survival of around $40 \%$. Historically, the survival for the subgroup requiring ECLS after stage 1 palliation for HLHS has been much lower, at less than $30 \%$. In fact many centres, until very recently, considered HLHS to be a relative contraindication for ECLS. However, it is becoming increasingly recognised that the period of myocardial "rest", and optimal systemic perfusion afforded by ECLS may have advantages over high dose inotrope therapy in borderline patients. In some centres this approach is becoming much more routine, with very encouraging outcomes. ${ }^{34}$ Therefore, although carrying a significant risk, ECLS can, if initiated promptly, improve the outcome in infants with impaired cardiopulmonary function after stage 1 palliation. ${ }^{35}$

\section{Vascular access}

Most infants require central venous access in the first days or weeks after stage 1 palliation, for drug delivery, and in some cases for parenteral nutrition. Line related venous thrombosis is a well recognised complication of central venous catheters, and this can have disastrous consequences in infants with HLHS. In particular, thrombosis of the superior caval vein can preclude any further surgery. Many units have now moved away from using internal jugular central venous catheters, in favour of direct atrial lines. Although there is little evidence base in the current literature, it would be worth considering the routine use of low dose intravenous heparin in infants with HLHS who have central venous lines.

\section{INTERSTAGE MORTALITY}

This term refers to deaths occurring after hospital discharge and prior to stage 2 palliation, the bi-directional cavopulmonary shunt. Most institutions quote an interstage mortality of $10-15 \%,{ }^{96}$ though early data would suggest that this figure may be lower with the conduit modification. ${ }^{25}$

Most interstage deaths are sudden and apparently unpredictable. Infants after stage 1 palliation require close and regular monitoring, with regular medical review. Ghanayem et al reported a reduction of interstage mortality from $16 \%$ to $0 \%$ in 81 consecutive infants with HLHS, following the introduction of systematic daily monitoring following discharge: ${ }^{37}$ parents maintained a log of daily weight and saturations. Oxygen saturations below $70 \%$ and/or failure to gain at least $20 \mathrm{~g}$ weight within three days triggered review by a physician. In our institution, all infants have weekly echos, and remain hospitalised, or in hospital accommodation until stage 2 palliation.

Stage 2 palliation is associated with very low mortality, and following this procedure patients show improved growth, and are low risk candidates for their Fontan completion 
(stage 3). A recent review of a cohort of 332 patients did not identify HLHS as an independent risk factor for mortality after the Fontan operation. ${ }^{38}$

\section{TRANSPLANTATION}

In some centres, the option of heart transplantation in early infancy is offered as an alternative to stage 1 palliation. Centres routinely performing transplantation have previously reported impressive early survival figures which would favour this option over stage 1 palliation. ${ }^{39}$ For the single reason of limited donor organ supply, primary transplantation is not a realistic option in most institutions outside North America.

Transplantation is not an easy option. Most infants awaiting transplantation require long term therapy with prostaglandin, may need repeated septal decompressions, and potentially other extracardiac procedures. Also, transplantation introduces a new set of considerations: the need for lifelong immune suppression, the accelerated onset of coronary artery disease, and the unknown question of the long term viability of a neonatal donor heart. Moreover, with improving survival rates for staged palliation, the relative benefits of heart transplantation have narrowed over the past decade. Thus, a study from the USA, of 2264 infants diagnosed with HLHS, showed a reduction in the proportion being transplanted during the past decade. ${ }^{40}$

\section{CONCLUSION}

Survival of patients with hypoplastic left heart syndrome has improved dramatically over the past 20 years, with many centres now quoting a survival after stage 1 palliation of over $80 \% .^{917} 19^{34}$ However, mortality for these infants remains higher than for other congenital heart defects requiring surgical intervention in the neonatal period. Three main reasons for this have been identified: preoperative instability, mainly caused by inadequate systemic oxygen delivery; mortality following stage 1 palliation; and out-of-hospital mortality whilst waiting for stage 2 palliation. In this article, we have emphasised the need to optimise systemic perfusion in the peri-operative period, the particular challenge caused by a restrictive ASD, and the benefits of prenatal diagnosis and early optimisation of medical management. We have also highlighted recent advances in the surgical technique of stage 1 palliation by using a right ventricle to pulmonary artery conduit, the role of heart transplantation, and the use of ECLS.

All in all, over recent years, the refinement of surgical techniques, with pre-emptive management and improved intensive and convalescent care, have dramatically changed the outlook for infants with HLHS and their families.

\section{ACKNOWLEDGEMENTS}

We would like to thank Dr Tom Karl, Director of Pediatric Cardiac Surgery, University College San Francisco, USA for kindly allowing us to include his illustrations for figs 1 and 2 .

\section{Authors' affiliations}

U Theilen, L Shekerdemian, Intensive Care Unit, Royal Children's Hospital, Parkville, Australia

Competing interests: none declared

\section{REFERENCES}

1 Norwood WI, Lang P, Hansen DD. Physiologic repair of aortic atresiahypoplastic left heart syndrome. N Engl J Med 1983;308:23-6.

2 Penny DJ, Shekerdemian LS. Management of the neonate with symptomatic congenital heart disease. Arch Dis Child Fetal Neonatal Ed 2001;84:F141-5.

3 Bove EL, Lloyd TR. Staged reconstruction for hypoplastic left heart syndrome. Contemporary results. Ann Surg 1996;224:387-95.
4 Canter CE, Moorehead S, Huddleston CB, et al. Restrictive atrial septal communication as a determinant of outcome of cardiac transplantation for hypoplastic left heart syndrome. Circulation 1993;88(5 pt 2):I1456-60.

5 Atz AM, Feinstein JA, Jonas RA, et al. Preoperative management of pulmonary venous hypertension in hypoplastic left heart syndrome with restrictive atrial septal defect. Am J Cardiol 1999;83:1224-8.

6 Lawrenson J, Eyskens B, Vlasselaers D, et al. Manipulating parallel circuits: the perioperative management of patients with complex congenital cardiac disease. Cardiol Young 2003;13:316-22.

7 Barnea O, Santamore WP, Rossi A, et al. Estimation of oxygen delivery in newborns with a univentricular circulation. Circulation 1998;98:1407-13.

8 McElhinney DB, Hedrick HL, Bush DM, et al. Necrotizing enterocolitis in neonates with congenital heart disease: risk factors and outcomes. Pediatrics 2000; 106:1080-7.

9 Azakie T, Merklinger SL, McCrindle BW, et al. Evolving strategies and improving outcomes of the modified Norwood procedure: a 10-year singleinstitution experience. Ann Thorac Surg 2001;72:1349-53.

10 Shime N, Hashimoto S, Hiramatsu N, et al. Hypoxic gas therapy using nitrogen in the preoperative management of neonates with hypoplastic left heart syndrome. Pediatr Crit Care Med 2000;1(1):38-41.

11 Chang AC, Zucker HA, Hickey PR, et al. Pulmonary vascular resistance in infants after cardiac surgery: role of carbon dioxide and hydrogen ion. Crit Care Med 1995;23:568-74.

12 Jobes DR, Nicolson SC, Steven JM, et al. Carbon dioxide prevents pulmonary overcirculation in hypoplastic left heart syndrome. Ann Thorac Surg 1992;54:150-1.

13 Malec E, Januszewska K, Kolcz J, et al. Right ventricle-to-pulmonary artery shunt versus modified Blalock-Taussig shunt in the Norwood procedure for hypoplastic left heart syndrome-influence on early and late haemodynamic status. Eur J Cardiothorac Surg 2003;23:728-34.

14 Tabbutt S, Ramamoorthy C, Montenegro LM, et al. Impact of inspired gas mixtures on preoperative infants with hypoplastic left heart syndrome during controlled ventilation. Circulation 2001;104(12 suppl 1):1159-64.

15 Norwood WI Jr. Hypoplastic left heart syndrome. Ann Thorac Surg 1991;52:688-95

16 Tweddell JS, Hoffman GM, Fedderly RT, et al. Phenoxybenzamine improves systemic oxygen delivery after the Norwood procedure. Ann Thorac Surg 1999;67:161-8.

17 Tweddell JS, Hoffman GM, Mussatto KA, et al. Improved survival of patients undergoing palliation of hypoplastic left heart syndrome: lessons learned from 115 consecutive patients. Circulation 2002;106(12 suppl 1):182-9.

18 Mahle WT, Clancy RR, McGaurn SP, et al. Impact of prenatal diagnosis on survival and early neurologic morbidity in neonates with the hypoplastic leff heart syndrome. Pediatrics 2001;107:1277-82.

19 Tworetzky W, McElhinney DB, Reddy VM, et al. Improved surgical outcome after fetal diagnosis of hypoplastic left heart syndrome. Circulation 2001;103:1269-73

20 Imoto $\mathrm{Y}, \mathrm{Kado} \mathrm{H}$, Shiokawa $\mathrm{Y}$, et al. Experience with the Norwood procedure without circulatory arrest. J Thorac Cardiovasc Surg 2001;122:879-82.

21 Sano S, Ishino K, Kawada M, et al. Right ventricle-pulmonary artery shunt in first-stage palliation of hypoplastic left heart syndrome. J Thorac Cardiovasc Surg 2003;126:504-10.

22 Pizarro C, Norwood WI. Right ventricle to pulmonary artery conduit has a favorable impact on postoperative physiology after Stage I Norwood: preliminary results. Eur J Cardiothorac Surg 2003;23:991-5.

23 Pizarro C, Malec E, Maher KO, et al. Right ventricle to pulmonary artery conduit improves outcome after stage I Norwood for hypoplastic left heart syndrome. Circulation 2003;108(suppl 1):11155-60.

24 Maher KO, Pizarro C, Gidding SS, et al. Hemodynamic profile after the Norwood procedure with right ventricle to pulmonary artery conduit. Circulation 2003;108:782-4.

25 Mair R, Tulzer G, Sames E, et al. Right ventricular to pulmonary artery conduit instead of modified Blalock-Taussig shunt improves postoperative hemodynamics in newborns after the Norwood operation. J Thorac Cardiovasc Surg 2003; 126:1378-84.

26 Hughes ML, Shekerdemian LS, Brizard CP, et al. Improved early ventricular performance with a right ventricle to pulmonary artery conduit in stage 1 palliation for hypoplastic left heart syndrome: evidence from strain Doppler echocardiography. Heart 2004;90:191-4.

27 Francis DP, Willson K, Thorne SA, et al. Oxygenation in patients with a functionally univentricular circulation and complete mixing of blood: are saturation and flow interchangeable? Circulation 1999;100:2198-203.

28 Tweddell JS, Hoffman GM, Fedderly RT, et al. Patients at risk for low systemic oxygen delivery after the Norwood procedure. Ann Thorac Surg 2000;69:1893-9

29 Hoffman GM, Ghanayem NS, Kampine JM, et al. Venous saturation and the anaerobic threshold in neonates after the Norwood procedure for hypoplastic left heart syndrome. Ann Thorac Surg 2000;70:1515-21.

30 Hoffman TM, Wernovsky G, Atz AM, et al. Efficacy and safety of milrinone in preventing low cardiac output syndrome in infants and children after corrective surgery for congenital heart disease. Circulation 2003; 107:996-1002

31 Poirier NC, Drummond-Webb JJ, Hisamochi K, et al. Modified Norwood procedure with a high-flow cardiopulmonary bypass strategy results in low mortality without late arch obstruction. J Thorac Cardiovasc Surg 2000;120:875-84.

32 Hoffman GM, Tweddell JS, Ghanayem NS, et al. Alteration of the critical arteriovenous oxygen saturation relationship by sustained afterload reduction after the Norwood procedure. J Thorac Cardiovasc Surg 2004;127:738-45. 
33 Bradley SM, Atz AM, Simsic JM. Redefining the impact of oxygen and hyperventilation after the Norwood procedure. J Thorac Cardiovasc Surg 2004; 127:473-80.

34 Ungerleider RM, Shen I, Yeh T, et al. Routine mechanical ventricular assist following the Norwood procedure-improved neurologic outcome and excellent hospital survival. Ann Thorac Surg 2004;77:18-22.

35 Pizarro C, Davis DA, Healy RM, et al. Is there a role for extracorporeal life support after stage I Norwood? Eur J Cardiothorac Surg 2001;19:294-301.

36 Ashburn DA, McCrindle BW, Tchervenkov $\mathrm{Cl}$, et al. Outcomes after the Norwood operation in neonates with critical aortic stenosis or aortic valve atresia. J Thorac Cardiovasc Surg 2003;125:1070-82.
37 Ghanayem NS, Hoffman GM, Mussatto KA, et al. Home surveillance program prevents interstage mortality after the Norwood procedure. J Thorac Cardiovasc Surg 2003;126:1367-77.

38 Gaynor JW, Bridges ND, Cohen Ml, et al. Predictors of outcome after the Fontan operation: is hypoplastic left heart syndrome still a risk factor? J Thorac Cardiovasc Surg 2002; 123:237-45.

39 Jenkins PC, Flanagan MF, Jenkins KJ, et al. Survival analysis and risk factors for mortality in transplantation and staged surgery for hypoplastic left heart syndrome. J Am Coll Cardiol 2000;36:1178-85.

40 Gutgesell HP, Gibson J. Management of hypoplastic left heart syndrome in the 1990s. Am J Cardiol 2002;89:842-6.

\section{IMAGES IN NEONATAL MEDICINE}

\section{Congenital absence of the left sternomastoid muscle}

$\mathrm{T}$

his baby was brought to medical attention at 1 hour of age. The birth was a normal spontaneous vaginal delivery, after an uneventful pregnancy. Examination revealed an absent left sternomastoid muscle with paradoxical movement of the soft tissues in the left supraclavicular space. This was more pronounced on crying, as illustrated in figs 1 and 2 . The rest of the clinical examination was unremarkable. The swelling seen superior to the clavicle was confirmed as being the herniating apex of the left lung.

A literature search found only one paper ${ }^{1}$ that describes a similar infant.

S Haroon

25 Magdalin Drive, Stanningley, Leeds LS28 6LD, UK

D Beverley

York District Hospital, Wigginton Road, York YO31 8HE, UK; david.w.beverley@york.nhs.uk

The child's parents have consented to the publication of this article.

\section{REFERENCE}

1 Bayne SR, Lehman JA, Crow JP. Lung herniation into the neck associated with congenital absence of the sternocleidomastoid muscle. J Pediatr Surg 1997;32:1754-6.

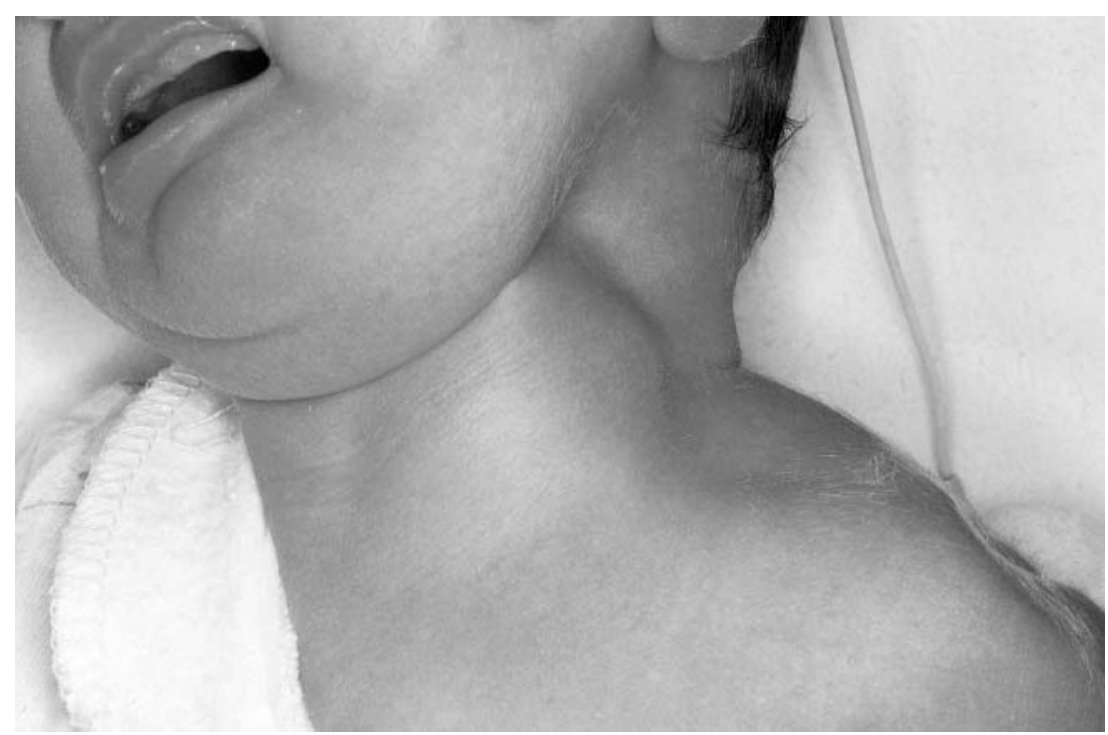

Figure 1 During expiration the pleural contents are herniating into the supraclavicular fossa. Permission to reproduce this photograph was obtained from the child's parents.

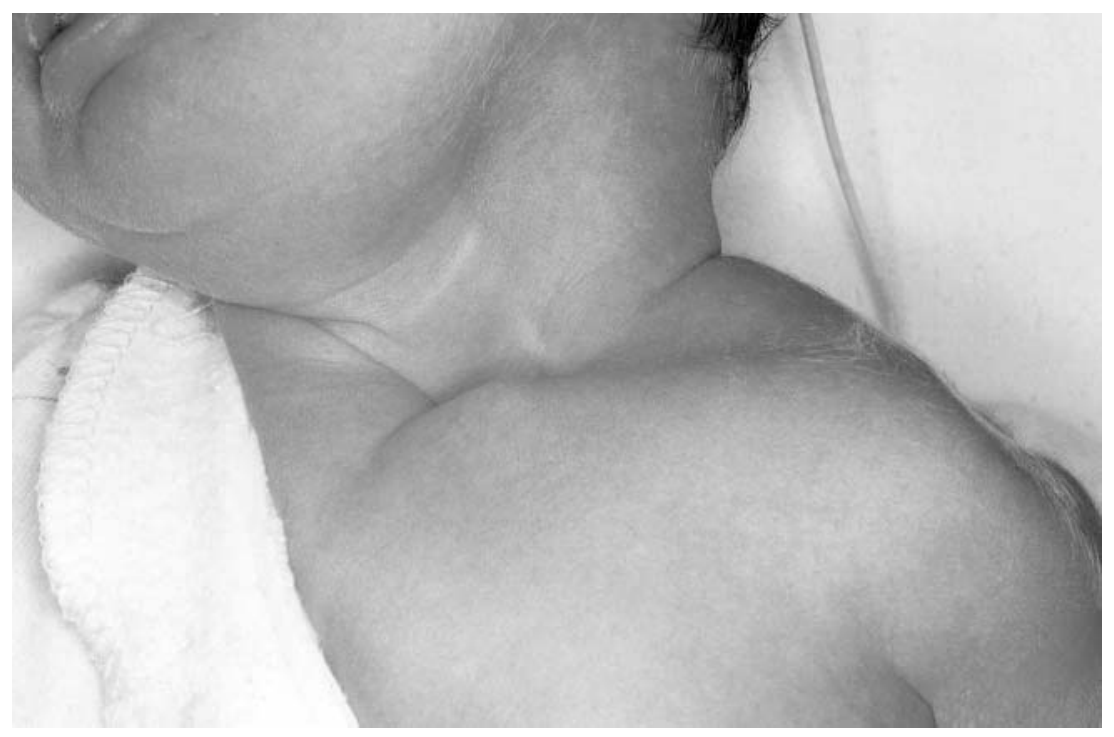

Figure 2 In inspiration there is paradoxical movement, with indrawing of the supraclavicular fossa. Permission to reproduce this photograph was obtained from the child's parents. 